\title{
Infección del virus de la hepatitis E en mujeres embarazadas
}

Hepatitis $E$ virus infection in pregnant women

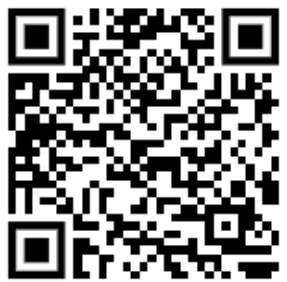

${ }^{1}$ Médico general, graduada de la Universidad de Costa Rica (UCR), médico investigadora independiente, San José, Costa

${ }^{2}$ Médico general, graduado de la Universidad de Ciencias Médicas (UCIMED), médico investigador independiente, San José, Costa.

${ }^{3}$ Médico general, graduada de la Universidad de Ciencias Médicas (UCIMED), médico investigadora independiente, San José, Costa.

${ }^{4}$ Médico general, graduada de la Universidad de Costa Rica (UCR), médico investigadora independiente, San José, Costa.

\author{
${ }^{1}$ Dra. Mariana Peña Miranda \\ Investigadora independiente , San José, Costa Rica \\ mariana.penam193@gmail.com \\ https://orcid.org/0000-0003-0753-7217 \\ ${ }^{2}$ Dr. Daniel Esteban Barquero Orias \\ Investigador independiente, San José, Costa Rica \\ daniel.barquero95@hotmail.com \\ https://orcid.org/0000-0001-7627-1358
}

${ }^{3}$ Dra. Valeria Nicole Molina Jiménez Investigadora independiente, San José, Costa Rica vale.molina06@gmail.com

https://orcid.org/0000-0001-5359-9473

${ }^{4}$ Dra. Jimena María Segura Guevara Investigadora independiente, San José, Costa Rica segurajime01@gmail.com

https://orcid.org/0000-0002-0887-3717

RECIBIDO CORREGIDO

ACEPTADO

$11 / 03 / 2019$

$16 / 03 / 2019$

$23 / 03 / 2019$

\section{RESUMEN}

El virus de la hepatitis $E$ es un agente infeccioso emergente que afecta tanto países en vías de desarrollo como países ya desarrollados. Este virus hepatotropo causa una amplia gama de cuadros clínicos; desde hepatitis viral aguda autolimitada hasta falla hepática fulminante. Las mujeres embarazadas se encuentran en mayor riesgo, por causas hormonales e inmunológicas, de una evolución tórpida de esta enfermedad aumentando la morbimortalidad materno-fetal. El manejo de la hepatitis $E$ en mujeres gestantes se limita a tratamiento de soporte, por lo que las medidas preventivas son la meta principal para esta población. Este artículo de revisión destaca la epidemiología, los diferentes cuadros clínicos y complicaciones obstétricas asociadas a la infección del virus de la hepatitis $E$ durante el embarazo. Además, se discute el rol de la progesterona y el sistema inmunológico en las pacientes afectadas por esta enfermedad. 
PALABRAS CLAVE: hepatitis; infección; embarazo; complicaciones del embarazo; falla hepática.

\section{ABSTRACT}

The hepatitis $E$ virus is an emergent infectious agent that affects both developing and developed countries. This hepatotropic virus causes a wide spectrum of clinical scenarios; from an acute auto limited viral hepatitis $E$ to a fulminant hepatic failure. Due to hormonal and immunological reasons, pregnant women are at increased risk of adverse outcomes of this disease related to higher maternal and fetal morbimortality. The main treatment for hepatitis $E$ infections in pregnant women is merely supportive, making prevention in this population the main goal. This article will review the epidemiology, clinical scenarios and obstetric complications associated with the hepatitis virus infection during pregnancy. In addition, the progesterone and immunological system role in this disease will be discussed.

KEYWORDS: hepatitis; infection; pregnancy; pregnancy complications; liver failure

\section{INTRODUCCIÓN}

Este artículo de revisión se realiza con el objetivo de presentar los cuadros clínicos que pueden ser causados por el virus de la hepatitis $E$ en la población gestante y destacar la fisiopatología detrás de la suceptibilidad de esta población, así como resaltar las medidas preventivas para evitar esta infección.

La hepatitis $E$ fue descubierta en Nueva Deli en 1955-1956, durante una epidemia de ictericia, en la que se descartaron los agentes etiológicos de la heptitis $A$ y hepatitis $B$, por lo que se identifica este virus como el causante la hepatitis no-A no-B, conocida hoy en día como la hepatitis E. (1)

Actualmente, el virus de la hepatitis $E$ es un agente infeccioso emergente responsable de la afección de 20.1 millones de personas, 70000 muertes y
3000 óbitos anualmente. Hoy en día se han registrados brotes 0 casos esporádicos en al menos 63 países del globo. (2)

El virus de la hepatitis $E$ es un $A R N$ virus que está clasificado dentro de la familia Hepeviridae, la cual se divide en dos géneros: Orthohepevirus, que afecta a mamiferos y aves, y Piscihepevirus, que se encuentra en los peces de la especie Oncorhynchus clarkii. El género Orthohepevirus, a su vez se divide en en cuatro subgéneros; el tipo $A$ es el que infecta a humanos, cerdos, jabalís, ciervos, suricatas, ratas, camellos, entre otros. Dentro de los Orthohepevirus A existen cinco genotipos: Gt1, Gt2, Gt3, Gt4 y Gt7 que afectan a los seres humanos; y Gt5 y Gt6 que se encuentran solamente en animales. (2) (3) (4)

Este virus causa dos escenarios clínicos distintos. Por un lado, se registran en la 
historia numerosas epidemias en paises en vías de desarrollo; causadas principalmente por el genotipo 1 en Asia y África, el genotipo 2 en México y África, y el genotipo 4 en Asia. Por otro lado, se reportan casos esporádicos tanto sintomáticos como asintomáticos en países desarrollados causados por el genotipo 3. (5)

El cuadro clínico de la hepatitis $E$ no varía mucho de los causados por otros virus hepatotrópos que causan hepatitis aguda, pero es importante resaltar las severas manifestaciones que se presentan en mujeres embarazas, especialmente durante el tercer trimestre, que lleva a una altísima mortalidad materna y fetal. (6)

\section{EPIDEMIOLOGÍA}

Las presentaciones endémicas del virus de la hepatitis $E$, en las que predominan los genotipos 1 y 2 , se localizan principalmente en India, China, Asia Central, Medio Oriente y África del norte. En estas regiones la forma de transmisión es fecal-oral, por lo que se asocia a contaminación de fuentes aquíferas o alimentos. (7) (8) (9)

En los países desarrollados, hasta hace 10 años solo se diagnosticaban casos importados de zonas endémicas, pero la última década se han diagnosticados numerosos casos autóctonos en regiones de Europa como Francia y Alemania, Estados Unidos, Japón y Australia. Estos casos esporádicos se asocian a varias vías de diseminación, entre ellas a la ingesta de alimentos porcinos crudos o mal cocidos. En los casos locales destacan los genotipos 3 y 4, principalmente. (7) (8) (9) (10)

\section{CUADRO CLÍNICO}

El virus de la hepatitis $E$ tiene un periodo de incubación de 15-60 días con una media de 40 días. Los principales signos y síntomas incluyen ictericia, malestar general, anorexia, fiebre, hepatomegalia y prurito. Esto acompañado de los hallazgos de laboratorio como una marcada elevación de transaminasas, aumento de la bilirubina sérica y una incremento moderado de la fosfatasa alcalina. (5)

Los cuadros clínicos varían desde individuos asintomáticos hasta casos de heptitis fulminante; predominantemente en mujeres embarazadas o pacientes con enfermedad hepática crónica de fondo (5). La falla hepática por el virus $E$ tiene una indicencia en individuos hombres o mujeres no embarazadas de el $<0.1 \%$, en comparación con una tasa presentación de $30-100 \%$ en mujeres embarazadas durante del segundo y tercer trimestre de gestación. (11)

En la mayoría de los casos, los cuadros de hepatitis $E$, ya sean endémicos 0 esporádicos, son autolimitados con una recuperación sintomática y bioquímica en 4 a 6 semanas. La cronificación del virus, aunque rara, se asocia principalmente a casos de pacientes inmunosupresos. (12)

\section{HEPATITIS E DURANTE EL EMBARAZO}

La hepatitis E, como otras infecciones, pueden complicar el curso del embarazo. Esta patología se asocia a ruptura prematura de membranas, hemorragia postparto, abortos espontáneos, óbitos, partos de pretérmino y niños pequeños 
para la edad gestacional. Dichas complicaciones ocurren en el $25 \%-56 \%$ de los casos de las mujeres infectadas.

(9)

En la investigación realizada por Shinde et al. en India, se encontró una prevalencia de hepatitis $E$ en $3.9 \%$ de 2140 mujeres embarazadas. La edad gestacional media al momento de la infección fue de 27.5 semanas, $63.4 \%$ de las pacientes adquirieron el virus en el tercer trimestre, por lo que se destaca en la literatura que esta enfermedad es una complicación con mayor incidencia durtante el tercer trimestre de gestación.

(11)

En este mismo estudio clínico, se demstró como las pacientes embarazadas infectadas por el virus de la hepatitis $E$ presentaban un incremento mayor en las bilirrubinas sércias en comparación a las mujeres no embarazadas, con medias de 11.9 $\mathrm{mg} / \mathrm{dly} 9.2 \mathrm{mg} / \mathrm{dl}$ respectivamente. (11)

En la investigación de Purabi et al., también en India, se resaltó el gran espectro de resultados clínicos que la infección por hepatitis $E$ puede causar. En dicho estudio, $58.14 \%$ de las pacientes con la complicación de falla hepática fulminante fallecieron; en comparación con una mortalidad nula en las pacientes con hepatitis viral aguda autolimitada. Los resultados fetales presentaron el mismo patrón, en donde $86.6 \%$ de los productos resultaron en óbitos en las madres con falla hepática fulmimante y $42 \%$ de las mujeres con hepatitis viral aguda sufrieron una muerte fetal. (13)

Posteriormente, Purabi et al. evidenciaron la mayor incidencia en parto prematuro en las pacientes con falla hepática fulminantes en comparación con la hepatitis aguda; con cifras del $73.3 \%$ y $42 \%$ respectivamente. (13)

Con respecto a los distintos gentipos del virus, se ha visto que los casos con evolución más tórpida se asocian principalmente al genotipo 1, característico de zonas endémicas. En zonas no endémicas se han visto algunos casos esporádicos de hepatitis $E$ en mujeres embarazadas pero ningún reporte de falla hepática fulminante; en estos casos se presenta predominantemente el genotipo 3. Estas incidencias sugieren que el genotipo y su repsectiva virulencia juegan un rol curcial en el pronóstico de esta infección en mujeres gestantes. (8)

\section{DESREGULACIÓN DE LA VÍA DE SEÑALIZACIÓN DEL RECEPTOR DE PROGESTERONA}

Por la característica propia del virus de la hepatitis $E$ de afectar en gran medida y magnitud a la población de mujeres embarazadas, se han propuesto teorías de los mecanismos fisiopatológicos que vuelven más propenso a este grupo de individuos.

El sistema inmunológico durante el embarazo sufre una serie de modificaciones que modulan las respuestas inmunes de las mujeres durante la gestación. Se observa una regulación hacia la alza de receptores de progesterona en las celulas natural killers en la decidua y en los linfocitos en la placenta. La progesterona activa la síntesis del factor de bloqueo inducido por progesterona (PIBF): una proteína que presenta efecto antiabortivo y es la encargada de ejercer el efecto inmunomodulador de la progesterona. (13) 
Tras el descubrimiento del rol fundamental de la progesterona como agente inmunomodulador, se ha propuesto la existencia de mutaciones genéticas del receptor de progesterona (PROGINS) como factor de riesgo para presentar complicaciones por el virus de la hepatitis E durante la gestación. (13) Purabi et al. realizaron un estudio clínico en la India con 100 gestantes portadoras del virus de la hepatitis E sobre la asociación de PROGINS y resultados negativos de la hepatitis $E$ en mujeres grávidas.

Se observó que las portadoras de estas mutaciones genéticas presentan una respuesta reducida a la hormona de progestrona, por lo cual a su vez disminuye la síntesis de PIBF. La presencia de estos haplotipos se documentó en $23.26 \%$ de las pacientes que sufrieron falla hepática fulminante $y$ solamente en el $4 \%$ de las mujeres embarazadas sanas. (13)

A su vez, se observó que la expresión del mRNA de los receptores de progesterona era considerablemente menor en las pacientes portadoras de PROGINS y que esto se asociaba, además, con una carga viral del virus de la hepatitis $E$ mayor a las pacientes con mayor presencia de receptores de progesterona no portadoras de PROGINS. (13)

Los niveles de PIBF medidos como mRNA siguieron también la tendencia mencionada anteriormente; siendo menor en las pacientes con hepatitis viral aguda y aún menor en las paciente con falla hepática fulminante comparado a las gestantes sanas. (13)

\section{ROL DE LAS CITOQUINAS EN LA HEPATITIS E}

Se presenta como teoría en la literatura, que una alteración en el control hormonal y la inmunidad es la responsable de la severidad de algunos casos de la infección por hepatitis E. (14)

Más específicamente, se ha investigado el rol de las citoquinas en esta patología. Las citoquinas tienen como rol fundamental actuar en contra de células tumorales, células infectadas por virus, actividad anti-viral directa y la estimulación de varias células efectoras del sistema inmune. La sobreactivación del sistema inmune, comandado por algunas citoquinas resulta deletereo para el desarrollo fetal, por lo que es ampliamente conocido la importancia de la tolerancia inmunológica materna durante el embarazo. (14) (15)

Las células $T$ se clasifican primordialmente en células ayudadoras tipo 1 (Th1) y células ayudadoras tipo 2 (Th2). Las primeras sintetizan citoquinas que inducen la respuesta inmune celular y las segundas, por su parte, activan la respuesta humoral. Se conoce, que durante el embarazo, la vía de Th1 se encuentra disminuida, la cual es deleterea para el producto de la gestación, y la Th2 aumentada. (14) (16) Dentro de la respuesta inmune de las Th1 se ha visto la secreción de varias citoquinas que son negativas para el desarrollo embrionario y fetal. El factor de necrosis tumoral alfa (TNF $\alpha$ ) causa necrosis de los embriones implantados y contracciones uterinas, el interferon gamma (IFN $\gamma$ ) inhibe el crecimiento trofoblástico in vitro, y ambos inhiben el desarrollo fetal y embrionario. Además, la 
presencia de citoquinas Th2 elevadas, como IL-6, se ha encontrado en tejido placentario, celulas amnióticas y deciduas de embarazos complicados por ruptura prematura de membranas, infección intrauterina y partos pretermino.

(11) (16)

Kumar et al. investigaron el rol de las citiquinas en mujeres embarazadas infectadas por el virus de la hepatitis $E$ en Nueva Deli, India. En este ensayo lograron demostrar una mayor concentración sérica de TNF $\alpha$, IL-6 y IFN $\gamma$ en las mujeres gestantes con hepatitis $\mathrm{E}$ que tuvieron una complicación como parto prematuro, productos pequeños para edad gestacional, óbitos o abortos, en comparación con las embarazadas sanas. La mayor elevación de estas citoquinas se observó en pacientes fallecidas o con óbitos. La presencia de falla hepática fulminante se asoció con aumento de TNF $\alpha$, IL-6 y IFN $\gamma$, con respecto a las pacientes con hepatitis aguda y las pacientes sanas. (14)

Se establece, entonces, en las mujeres gestantes infectadas por hepatitis $E$ un aumento notorio tanto de las citoquinas inflamatorias Th1 TNF $\alpha$ y IFN $\gamma$, como antinflamatorias Th2 IL-6 y TGF- $\beta 1$. Estas últimas secretadas probablemente para contener la respuesta inflamatoria mediada por su contraparte las celulas ayudadores tipo 1. (14)

\section{HEPATITIS E EN NEONATOS}

En 1955 Khuroo et al. documentaron por primera vez una transmisión vertical del virus de la hepatitis $E$ usando métodos moleculares y serológicos. ARN del virus fue encontrado en el cordón umbilical de cinco de los ocho neonatos de Kashmiri de madres portadoras de hepatitis $E$ durante la gesta. Todos los infantes presentaban elevación de transaminasas hepáticas al nacer y dos fallecieron un día posterior a su nacimiento por hipoglicemia e hipotermia. Viremia en suero, anitcuerpos tipo $\lg \mathrm{M}$ y datos bioquímicos de hepatitis persistieron por varias semanas tras el nacimiento, por lo que se descartó la contaminación de la sangre del cordón umbilical con sangre materna. (17).

El mismo grupo de investigadores realizó un reporte años después de 19 neonatos, en 15 de estos se documentó IgM anti hepatitis $\mathrm{E}$ o RNA del virus en el cordón umbilical. De esta muestra; siete presentaron hepatitis ictérica, cinco hepatitis anictérica, y tres hiperbilirrubinemia pero enzimas hepáticas normales. Seis infantes fallecieron de hipoglicemia e hipertermia y los restantes nueve niños tuvieron un cuadro autolimitado con normalización bioquímica de pruebas de función hepática en 8 semanas. No se reportó ningún caso de hepatitis $\mathrm{E}$ crónica. (18) Numerosos estudios posteriores han demostrado tasas de transmisión similares. (19) Se han reportado casos de autopsias de óbitos fetales en donde se evidencia necrosis severa en tejido hepático por lo que se cree que los neonatos pueden sufrir fallo hepático fulminante in utero como resultado de hepatitis E. (19)

Al contrario de la hepatitis $B$, en la cual de deben de tomar medidas preventivas para evitar la cronificación del virus en los neonatos afectados, la hepatitis $E$ no ha provocado casos en los que se demuestre la cronificación del padecimiento. Hepatitis E crónica 
solamente se ha documentado en pacientes inmunosupresos. (18)

En los últimos años se han visto reportes de caso que documentan ARN del virus de la hepatitis en la leche materna. Por ejemplo, Rivero-Juarez et al. aislaron el patógeno en lecha materna y suero en titulaciones iguales en una mujer durante un cuadro de hepatitis $\mathrm{E}$ aguda autolimitada que resolvió sintomática y bioquímicamente en cuatro semanas. La paciente se encontraba dando lactancia a su hijo de 18 meses al momento de la infección, por lo que los médicos tratantes suspendieron la lactancia. (20)

\section{TRATAMIENTO}

Actualmente no existe ningún tratamiento contra el virus de la hepatitis $E$ que se pueda utilizar durante el embarazo. El tratamiento de la población no embarazada se realiza con ribavirin asociado o no con interferón pegilado, pero este esquema se encuentra fuertemente contraindicado durante la gestación. Por este motivo, el manejo de esta infección en mujeres grávidas debe ir enfocado a la hospitalización y tratamiento de soporte. (2)

\section{PREVENCIÓN}

Actualmente se plantean dos intervenciones claves en la prevención dela hepatitis $\mathrm{E}$ a nivel de la población general: medidas sanitarias y la vacunación. (2)

Como medidas sanitarias básicas, se recomienda a mujeres embarazadas que viajen a zonas endémicas, seguir precauciones alimenticias, como beber solamente agua embotellada, evitar frutas y vegetales sin pelar y sin lavar, además de seguir un riguroso lavado de manos. (21)

La vacunación contra la hepatitis $E$, es una realidad solamente en China, donde se aprobó una vacuna recombinante de proteínas de las cápsides víricas tras probar efectividad y seguridad en ensayos clínicos de segunda y tercera fase. Esta vacuna no ha sido aprobada para el uso en embarazo, pues solamente fue probada en pacientes sanos mayores de 16 años. (22) (23) (24) Los científicos Joshi et al. probaron una vacuna recombinante en ratones en el séptimo día de gestación y concluyeron que esta fue segura e inmunogénica en la población en estudio. A pesar de esto, se necesitan de mayores investigaciones en seres humanos para la aprobación de este uso. (22) (23)

\section{CONCLUSIONES}

Según la bibliografía revisada el virus de la hepatitis $E$ afecta hoy en día a numerosos países en vías de desarrollo de manera endémica, como a paises desarrollados en forma de casos aislados.

Es de destacar las severas repercusiones que esta infección provoca en las mujeres embarazdas; predominantemente durante el tercer trimestre. Su cuadro clínico va desde hepatitis no ictéricas hasta falla hepática fúlminante letal en mujeres embarazadas, asociados además a resultados obstétricos adversos. Como se destacó a lo largo de este trabajo, esta variabilidad se debe a los diferentes genotipos del virus y aspectos 
inmunogénicos y hormonales que vuelven a ciertos pacientes más vulnerables a un desenlace tórpido de la enfermedad.

Como tratamiento base de las mujeres embarazadas portadoras de hepatitis $E$, se recomienda la hospitalización y el soporte vital; por lo que se concluye que como pilar fundamental, se debe prestar importancia a la prevención de esta enfermedad con medidas higiénicas y la cocción adecuada de los alimentos de origen animal.

\section{REFERENCIAS}

1. Teshale EH. Hepatitis E: Epidemiology and prevention. World Journal of Hepatology. 2011;3(12):285. https://doi.org/10.4254/wih.v3.i12.285

2. Pérez-Gracia MT, Suay-García B, Mateos-Lindemann ML. Hepatitis E and pregnancy: current state. Reviews in Medical Virology. 201703 20;27(3):e1929. https://doi.org/10.1002/rmv.1929

3. Wedemeyer H, Pischke S, Manns MP. Pathogenesis and Treatment of Hepatitis E Virus Infection. Gastroenterology. 2012 05;142(6):1388-1397.e1. https://doi.org/10.1053/j.gastro.2012.02.014

4. Khuroo MS, Khuroo MS. Hepatitis E: an emerging global disease - from discovery towards control and cure. Journal of Viral Hepatitis. 201509 06;23(2):68-79. https://doi.org/10.1111/jvh.12445

5. Teshale E, Hu D, Holmberg S. The Two Faces of Hepatitis E Virus. Clinical Infectious Diseases. 2010 08;51(3):328-334. https://doi.org/10.1086/653943

6. Kar P, Borkakoti J, Hazam RK, Asim M, Kumar A. Does High Viral Load of Hepatitis E Virus Influence the Severity and Prognosis of Acute Liver Failure During Pregnancy?. Journal of Clinical and Experimental Hepatology. 2013 03;3(1):S2. https://doi.org/10.1016/j.jceh.2013.03.005

7. Hakim MS, Wang W, Bramer WM, Geng J, Huang F, de Man RA, Peppelenbosch MP, Pan Q. The global burden of hepatitis E outbreaks: a systematic review. Liver International. 201609 09;37(1):19-31. https://doi.org/10.1111/liv.13237

8. Aggarwal R. Clinical presentation of hepatitis E. Virus Research. 2011 Oct;161(1):15-22. https://doi.org/10.1016/j.virusres.2011.03.017

9. Bouthry E, Benachi A, Vivanti AJ, Letamendia E, Vauloup-Fellous C, Roque-Afonso A. Autochthonous Hepatitis E during Pregnancy, France. Emerging Infectious Diseases. 2018 08;24(8):1586-1587. https://doi.org/10.3201/eid2408.180105

10. Tabatabai J, Wenzel J, Soboletzki M, Flux C, Navid MH, Schnitzler P. First case report of an acute hepatitis E subgenotype $3 c$ infection during pregnancy in Germany. Journal of Clinical Virology. 2014 09;61(1):170-172. https://doi.org/10.1016/j.jcv.2014.06.008

11. Patil T, Deshpande A, Gulhane R, Bansod Y, Shinde N, Patil M. Clinical profile, maternal and fetal outcomes of acute hepatitis e in pregnancy. Annals of Medical and Health Sciences Research. 2014;4(8):133. https://doi.org/10.4103/2141-9248.138033

12. Kamar N, Dalton HR, Abravanel F, Izopet J. Hepatitis E Virus Infection. Clinical Microbiology Reviews. 201401 01;27(1):116-138. https://doi.org/10.1128/cmr.00057-13 
13. Bose PD, Das BC, Kumar A, Gondal R, Kumar D, Kar P. High viral load and deregulation of the progesterone receptor signaling pathway: Association with Hepatitis E-related poor pregnancy outcome. Journal of Hepatology. 2011 06;54(6):1107-1113. https://doi.org/10.1016/j.jhep.2010.08.037

14. Kumar A, Devi SG, Kar P, Agarwal S, Husain SA, Gupta RK, Sharma S. Association of cytokines in hepatitis $\mathrm{E}$ with pregnancy outcome. Cytokine. 2014 01;65(1):95-104. https://doi.org/10.1016/j.cyto.2013.09.022

15. Lhomme S, Marion O, Abravanel F, Chapuy-Regaud S, Kamar N, Izopet J. Hepatitis E Pathogenesis. Viruses. 201608 05;8(8):212. https://doi.org/10.3390/v8080212

16. Kmush BL, Ali H, Engle RE, West K, Shaikh S, Christian P, Mehra S, Schulze K, Klein SL, Purcell RH, Li W, Labrique A, Wu L, Nelson K. The Association of Cytokines and Micronutrients with Hepatitis E Virus Infection During Pregnancy and the Postpartum Period in Rural Bangladesh. The American Journal of Tropical Medicine and Hygiene. 201601 06;94(1):203-211. https://doi.org/10.4269/ajtmh.15-0238

17. Khuroo M, Kamali S, Jameel S. Vertical transmission of hepatitis E virus. The Lancet. 1995 04;345(8956):1025-1026. https://doi.org/10.1016/s0140-6736(95)90761-0

18. Khuroo MS, Kamili S, Khuroo MS. Clinical course and duration of viremia in vertically transmitted hepatitis E virus (HEV) infection in babies born to HEV-infected mothers. Journal of Viral Hepatitis. 2009 07;16(7):519-523. https://doi.org/10.1111/j.1365-2893.2009.01101.x

19. Krain LJ, Labrique AB, Atwell JE, Nelson KE. Fetal and Neonatal Health Consequences of Vertically Transmitted Hepatitis E Virus Infection. The American Journal of Tropical Medicine and Hygiene. 201402 05;90(2):365-370. https://doi.org/10.4269/ajtmh.13-0265

20. Rivero-Juarez A, Frias M, Rodriguez-Cano D, Cuenca-López F, Rivero A. Isolation of Hepatitis E Virus From Breast Milk During Acute Infection: Table 1.. Clinical Infectious Diseases. 201603 29;62(11):1464.21464. https://doi.org/10.1093/cid/ciw186

21. Chaudhry S, Verma N, Koren G. Hepatitis E infection during pregnancy. Canadian Family Physician [Internet]. 2015 [citado 22 Febrero 2019];61(7):607-608. Disponible en: http://www.cfp.ca/content/61/7/607

22. Joshi SS, Arankalle VA. Enhanced humoral response in pregnant mice immunized with liposome encapsulated recombinant neutralizing epitope protein of Hepatitis- E virus. Virology Journal. 201505 03;12(1). https://doi.org/10.1186/s12985-015-0302-8

23. Li S, Zhao Q, Wu T, Chen S, Zhang J, Xia N. The development of a recombinant hepatitis E vaccine HEV 239. Human Vaccines \& Immunotherapeutics. 201502 25;11(4):908-914. https://doi.org/10.1080/21645515.2015.1008870

24. Goel A, Aggarwal R. Advances in hepatitis E - II: Epidemiology, clinical manifestations, treatment and prevention. Expert Review of Gastroenterology \& Hepatology. 201605 20;10(9):1065-1074. https://doi.org/10.1080/17474124.2016.1185365 